\section{Birth cohort differences in hypertension control in a Brazilian population of older elderly: the Bambuí Cohort Study of Aging (1997 and 2008)}

\author{
Diferenças de coorte por nascimento no controle \\ da hipertensão entre idosos mais velhos: Estudo \\ de Coorte de Idosos de Bambuí (1997 e 2008)
}

\author{
1 Núcleo de Estudos \\ em Saúde Pública e \\ Envelhecimento, Fundação \\ Oswaldo Cruz/Universidade \\ Federal de Minas Gerais, \\ Belo Horizonte, Brasil. \\ 2 Escola de Enfermagem \\ Universidade Federal de \\ Minas Gerais, Belo Horizonte, \\ Brasil. \\ Correspondence \\ J. O. A. Firmo \\ Núcleo de Estudos em Saúde \\ Pública e Envelhecimento, \\ Fundação Oswaldo Cruzl \\ Universidade Federal de Minas \\ Gerais. \\ Av. Augusto de Lima 1715, 6 \\ andar, Belo Horizonte, $M G$ \\ 30190-002, Brazil. \\ firmoj@cpqrr.fiocruz.br
}

\begin{abstract}
We examined for cohort differences in hypertension control between participants in the Bambui Cohort Study of Aging of aging born 1916-1926 and 1927-1937. Participants included hypertensive elderly aged 71-81 at baseline $(n=313)$ and at 11 th wave follow up $(n=484)$. Prevalence of hypertension awareness $(70.9 \%$ and $81.2 \%$, respectively), median medical appointments in previous 12 months (2 and 3, respectively) and antihypertensive drug use $(74.4 \%$ and $90.7 \%$ respectively) increased significantly from older to younger cohort. However, prevalence of appropriately controlled hypertension among those treated $(<140 /<90 \mathrm{mmHg})$ was similar in both cohorts $(44.6 \%$ and $40.1 \%, p=0.255)$. Multivariate analysis returned schooling as the only factor independently associated with appropriately controlled hypertension. Despite increased medical appointments and drug use in the recent cohort, the prevalence of appropriately controlled hypertension remained as low as in the older cohort.
\end{abstract}

Hypertension; Aged; Cohort Studies
Josélia O. A. Firmo 1

Sérgio Viana Peixoto 1

Antônio Ignácio de Loyola Filho 1,2

Elizabeth Uchôa 1

Maria Fernanda Lima-Costa 1

\section{Introduction}

Worldwide, arterial hypertension is the main risk factor for mortality and the third most important cause ${ }^{1}$ of years lived with disability. Prevalence of arterial hypertension is high in the overall population, and increases markedly with age. It is the most common chronic disease among older adults, with prevalence of $60 \%$ or more, both in high-income countries and in Latin America and the Caribbean 2. The World Health Organization (WHO) estimated in 2002 that at least $50 \%$ of cardiovascular diseases and $75 \%$ of strokes result from high blood pressure 3 . Because of its high prevalence and severe consequences, efforts have been made worldwide to increase detection and control of existing arterial hypertension 4,5,6,7.

Proper control of arterial hypertension is defined by systolic and diastolic pressures of less than 140 and $90 \mathrm{mmHg}$, respectively, among persons undergoing drug treatment. In the United States, results of the National Health and Nutrition Examination Survey (NHANES) showed that, in the overall population, prevalence of proper control of arterial hypertension increased among those undergoing treatment from $51 \%$ in 1988-94 to $69 \%$ in 2007 . However, those observations were not corroborated in a more recent study based on the same survey, which found prevalence of appropriate control of arterial pressure among patients treated to be $44 \%$ for the period from 2005 to 2008 9. In Ontario, Canada, preva- 
lence of proper control of arterial hypertension among patients treated was $66 \%$ in 2006 , which is higher than observed in other population based surveys conducted in the early 1990s (12\%) 10 . The studies above showed discrepant results for control of arterial hypertension among older adults as compared with younger adults. While the first United States study 8 found that, among patients 60 years old or older, controlled arterial hypertension was less prevalent than among young and middle-age adults, the second study 9 found better control of arterial hypertension in the older and middle-aged adult groups than among the youngest age group, which agrees with what was observed in Canada 10. In middle-income countries, there is little information on appropriate control of arterial hypertension. One study in Mozambique (Africa) showed that, in 2005, in the overall population, $40 \%$ of hypertensive patients treated displayed appropriate arterial pressure levels 11 .

To our knowledge, there are no populationbased studies examining trends in appropriate control of arterial hypertension among older adults in Brazil. One cross-sectional study conducted on the baseline of the cohort study of older adults in Bambuí, Minas Gerais State, showed prevalence of arterial hypertension to be $62 \%$. Among the 919 participants with arterial hypertension, 704 (77\%) knew they were hypertensive, 578 (63\%) were using some anti-hypertensive drug and, of these, 225 (39\%) displayed appropriately controlled arterial hypertension 12 .

The present study used baseline and $11^{\text {th }}$ wave data on the Bambuí cohort mentioned above, in order to examine for birth cohort differences in prevalence of appropriate control of arterial hypertension among older elderly adults, and in associated factors.

\section{Methodology}

\section{Area studied}

The cohort study has being conducted in the town of Bambuí (population approximately 15,000), in Minas Gerais State. The cohort baseline was established in 1997, since when followup is performed annually on all participants by interview and death certificate review. Measurement of arterial pressure and other biological measures were taken at the baseline and at 2000, 2002 and 2008 follow-up. Further details are available in previous publications 13,14.

When the cohort baseline was established, the town of Bambuí had one 62-bed hospital, 15 doctors (1 per 1,000 population), and a polyclinic that offered 24-hour emergency care. In 2003, the Family Health Strategy (FHS) was introduced in the town, for which four teams were set up. In 2006, two further teams were added to the program, and drug distribution began under the FHS.

The Bambuí cohort study of older adults was approved (for initial procedures) by the Ethics Research Committee of the Oswaldo Cruz Foundation (Fundação Oswaldo Cruz - Fiocruz), Rio de Janeiro, and (for procedures not contemplated in the original project) by the Ethics Research Committee of the René Rachou Research Center of Fiocruz (Centro de Pesquisas René Rachou), Belo Horizonte. Baseline participants signed a free, informed consent form, which was renewed at all study follow-up points.

\section{Population studied}

The population for the baseline cohort was identified by means of a complete census of the town performed in November and December 1996. Of the 1,742 residents aged 60 years or more on 1 January 1997, 1,606 participated at the baseline and 1,492 had their arterial pressure measured. Loss to follow-up in the first ten years was $6 \% 13,14$.

For the present study, all hypertensive participants aged from 71 to 81 years at the baseline and at $11^{\text {th }}$ year follow-up were selected (that is, those born in 1916-1926 and in 1927-1937, respectively). Hypertension was considered to be given by systolic pressure $\geq 140 \mathrm{mmHg}$ and/or diastolic pressure $\geq 90 \mathrm{mmHg}$, and/or anti-hypertensive drug use 15 .

\section{Measurements of arterial pressure and drug use}

Three measurements of arterial pressure were taken at 2-minute intervals, after 5 minutes rest, with the individual seated and with the arm supported at heart level. These measurements were taken in a quiet, isolated room with controlled temperature. The first was taken after at least 30 minutes without drinking coffee or smoking. Arterial pressure was considered to be the mean of the second and third measurements 15 . The following instruments were used: Tycos 5097 sphygmomanometers (Welch Allyn Tycos 5097 30, Tycos, Arden, USA) and Littman Cardiology II stethoscopes (3M Medical Devices, St. Paul, USA). Arterial pressure was measured at Fiocruz advance post in Bambuí by trained technicians. The technicians' training included use of videos, double auscultation, and exercises to gauge inter- and intra-observer variability. The same procedures were followed in 1997 and 2008. 
Use of drugs was ascertained by home interview, which included examining the drug packaging or medical prescription. Drugs were classified using the Anatomical Therapeutical Chemical Index (ATC/DDD Index) 16. Drugs of the following drug classes were considered anti-hypertensives: diuretics (CO3), beta blocking agents (CO7), calcium channel blockers (CO8), agents acting on the renin-angiotensin system (CO9), and antihypertensives (CO2).

\section{Other variables}

Other variables considered in this study were: age, sex, schooling (complete years), leisuretime physical activities, current smoking, number of medical appointments in the previous 12 months, history of medical diagnosis for arterial hypertension, and body mass index (BMI). Sufficient leisure-time physical activity was defined by the participant's reporting having performed exercises of any intensity for at least 20-30 minutes, three times or more a week in the previous 90 days. Tobacco use was defined as consumption of at least 100 cigarettes ever, and continuing with the habit at present. Participants were considered to know they suffered from hypertension if they reported having been so informed by a doctor. BMI was defined as weight over height squared. Further details are available in previous publications 13,14.

Controlled arterial hypertension was defined by values of systolic and diastolic pressure of less than 140 and $90 \mathrm{mmHg}$, respectively, among those using anti-hypertensive drugs 15 .

\section{Data analysis}

Unadjusted analysis was based on the Pearson chisquare test, Student t-test and Mann-Whitney test for differences in frequencies, means and medians, respectively. Analysis of the factors associated with appropriate control of arterial hypertension was based on prevalence ratios (PRs) and 95\% confidence intervals $(95 \% \mathrm{CI})$ estimated by Poisson regression with robust variance. All analyses were performed using Stata 11.0 software (Stata Corp., College Station, USA).

\section{Results}

The arterial pressure of $93.3 \%$ of cohort participants (492/459) was measured in 1997, and $92.9 \%$ (576/620) in 2008. In both years, no statistically significant differences ( $p>0.05$ ) were observed in age and sex between those who had their arterial pressure measured and those who did not. Preva- lence of arterial hypertension $(\geq 140 / \geq 90 \mathrm{mmHg}$ and/or treatment) increased from $68.2 \%$ in 1997 to $84 \%$ in 2008 ( $\mathrm{p}=0.029)$.

The study participants' characteristics are shown in Table 1. The two cohorts did not differ in mean age or the proportion of women. In the more recent cohort (born 1927-1937), as compared with the previous one (born 1916-1926), significant increases were observed in the proportion of those with 4 years' or more schooling, and of those with sufficient leisure-time physical activity, in addition to an increase in mean BMI and median number of medical appointments in the previous 12 months. Prevalence of smoking use halved (from $16 \%$ to $8.9 \%$ ). Among the older adults of the more recent cohort, there was a greater prevalence of those who knew they were hypertensive than in the earlier cohort $(81.2 \%$ against $70.9 \%$ ) and of those who used anti-hypertensive drugs $(90.7 \%$ against $74.4 \%)$.

Table 2 shows the values of systolic and diastolic pressure by birth cohort and sex. In joint analyses for both sexes, no statistically significant differences $(p>0.05)$ were observed between the cohorts in prevalence of arterial pressure controlled at levels below $140 / 90 \mathrm{mmHg}$ (44.6\% and $40.1 \%$, respectively) or at levels below $160 / 100 \mathrm{mmHg}(76.8 \%$ and $74.9 \%$, respectively), or in mean systolic pressure $(143.4 \mathrm{mmHg}$ and $145.6 \mathrm{mmHg}$, respectively). These results were observed consistently among men and women. Mean diastolic pressure was lower in the more recent cohort $(79.5 \mathrm{mmHg})$ than in the older cohort (82.5mmHg); and that decrease was observed among the men, but not among the women. Table 3 shows the results of multivariate analysis of the factors associated with appropriate control of arterial hypertension stratified by birth cohort. Only four or more years' schooling showed an independent association with appropriate control of arterial hypertension, and that association was observed consistently in the two cohorts (PR $=1.34$; 95\%CI: $1.00-1.79$ and PR $=1.26$; 95\%CI: 1.00-1.58, respectively). Sex, leisure-time physical activity, current smoking use, BMI and number of medical appointments in the previous 12 months showed no significant associations with appropriate control of arterial hypertension [PR $(95 \% \mathrm{CI})]$, ranging from 0.89 (0.68-1.17) to $1.26(0.90-1.76)$ in the older cohort, and PR adjusted for sex (95\%CI) ranging from $0.85(0.54-1.34)$ to $1.28(0.87-1.87)$ in the recent cohort. 
Characteristics of study participants, by birth cohort. The Bambui Cohort Study of Aging, 1997 and 2008.

\begin{tabular}{|c|c|c|}
\hline \multirow[t]{2}{*}{ Characteristics } & \multicolumn{2}{|c|}{ Cohort } \\
\hline & $\begin{array}{c}1916-1925 \\
(n=313)\end{array}$ & $\begin{array}{c}1927-1937 \\
(n=484)\end{array}$ \\
\hline Age [mean (SD)] & $75.1(3.1)$ & $75.1(3.0)$ \\
\hline Female & 65.5 & 66.7 \\
\hline Four or more years' schooling & 29.8 & 38.0 * \\
\hline Leisure-time physical activity in previous 90 days & 12.5 & $27.1 \star \star$ \\
\hline Current smoking & 16.0 & $8.9 \star \star \star$ \\
\hline $\mathrm{BMI}\left(\mathrm{kg} / \mathrm{m}^{2}\right)[$ mean $(\mathrm{SD})]$ & $25.2(4.9)$ & $26.1(5.3)$ * \\
\hline Number of medical appointments in previous 12 months, median (P25-P75) & $2(1-4)$ & $3(2-5) \star \star$ \\
\hline Aware hypertensive & 70.9 & 81.2 ** \\
\hline Regular use of anti-hypertensive drug & 74.4 & $90.7^{\star \star}$ \\
\hline
\end{tabular}

BMI: body mass index; SD: standard deviation; P25 and P75: 25 and 75 percentiles, respectively.

* $\mathrm{p}<0.05$

** $p<0.001$;

$\star \star \star ~ p<0.01$

Note: results in percentages, except where indicated.

Table 2

Mean systolic and diastolic pressure values, by birth cohort and sex. The Bambuí Cohort Study of Aging, 1997 and 2008.

\begin{tabular}{|c|c|c|c|c|c|c|}
\hline \multirow[t]{2}{*}{ Variables } & \multicolumn{2}{|c|}{$\begin{array}{l}\text { All } \\
\text { Cohorts }\end{array}$} & \multicolumn{2}{|c|}{$\begin{array}{l}\text { Male } \\
\text { Cohorts }\end{array}$} & \multicolumn{2}{|c|}{$\begin{array}{l}\text { Female } \\
\text { Cohorts }\end{array}$} \\
\hline & $\begin{array}{l}1916-1926 \\
(n=233)\end{array}$ & $\begin{array}{c}1927-1937 \\
(n=439)\end{array}$ & $\begin{array}{c}1916-1926 \\
(n=65)\end{array}$ & $\begin{array}{c}1927-1937 \\
(n=138)\end{array}$ & $\begin{array}{c}1916-1926 \\
(n=168)\end{array}$ & $\begin{array}{c}1927-1937 \\
(n=301)\end{array}$ \\
\hline $\begin{array}{l}\text { Systolic pressure and } \\
\text { diastolic pressure < } 140 \text { and } \\
<90 \mathrm{mmHg}(\%)\end{array}$ & 44.6 & 40.1 & 49.2 & 44.2 & 42.9 & 38.2 \\
\hline $\begin{array}{l}\text { Systolic pressure and } \\
\text { diastolic pressure < } 160 \text { and } \\
<100 \mathrm{mmHg}(\%)\end{array}$ & 76.8 & 74.9 & 72.3 & 78.3 & 78.6 & 73.4 \\
\hline $\begin{array}{l}\text { Mean systolic pressure } \\
\text { in } \mathrm{mmHg}(\mathrm{SD})\end{array}$ & $\begin{array}{l}143.4 \\
(22.7)\end{array}$ & $145.6(21.8)$ & $\begin{array}{l}143.1 \\
(25.6)\end{array}$ & $\begin{array}{l}143.8 \\
(20.4)\end{array}$ & $\begin{array}{l}143.5 \\
(21.6)\end{array}$ & $146.4(22.4)$ \\
\hline $\begin{array}{l}\text { Mean diastolic pressure } \\
\text { in } \mathrm{mmHg}(\mathrm{SD})\end{array}$ & $82.5(12.1)$ & $79.5(12.0)$ * & 83.5 (12.3) & 80.8 (11.3) & $82.0(12.0)$ & $79.0(12.2)$ * \\
\hline
\end{tabular}

SD: standard deviation.

* $p<0.01$.

\section{Discussion}

The results of this study show that, in the two cohorts studied, no changes occurred in the prevalence of appropriate control of arterial hypertension among hypertensive older adults using anti-hypertensive drugs. On the other hand, awareness of being hypertensive and use of medication for arterial hypertension were observed to increase significantly in the recent cohort in comparison to the earlier cohort.

To complement this, our analysis considered other indicators of success in controlling arterial hypertension among those in treatment. These 
Multivariate analysis of factors associated with appropriate control of arterial pressure (systolic pressure $<140 \mathrm{mmHg}$ and diastolic pressure $<90 \mathrm{mmHg}$ ) stratified by birth cohort. The Bambuí Cohort Study of Aging, 1997 and 2008.

\begin{tabular}{|c|c|c|c|c|c|c|}
\hline \multirow[t]{3}{*}{ Variables } & \multicolumn{3}{|c|}{ 1916-1926 cohort } & \multicolumn{3}{|c|}{ 1927-1937 cohort } \\
\hline & \multirow[t]{2}{*}{ Treated } & \multicolumn{2}{|c|}{ Appropriate control } & \multirow[t]{2}{*}{ Treated } & \multicolumn{2}{|c|}{ Appropriate control } \\
\hline & & n (\%) & PR $(95 \% \mathrm{Cl})$ & & n (\%) & PR $(95 \% \mathrm{Cl})$ \\
\hline \multicolumn{7}{|l|}{ Sex } \\
\hline Male & 65 & $32(49.2)$ & 1.00 & 138 & $61(44.2)$ & 1.00 \\
\hline Female & 168 & $72(42.9)$ & $0.87(0.64-1.18)$ & 301 & 115 (38.2) & $0.86(0.68-1.09)$ \\
\hline \multicolumn{7}{|c|}{ Schooling (years) } \\
\hline $0-3$ & 160 & $64(40.0)$ & 1.00 & 272 & $99(36.4)$ & 1.00 \\
\hline$\geq 4$ & 72 & $39(54.2)$ & $1.34(1.00-1.79)$ * & 167 & $77(46.1)$ & $1.26(1.00-1.58)$ ** \\
\hline \multicolumn{7}{|c|}{ Leisure-time physical activity in previous } \\
\hline \multicolumn{7}{|l|}{90 days } \\
\hline No & 201 & $91(45.3)$ & 1.00 & 324 & $133(41.1)$ & 1.00 \\
\hline Yes & 32 & $13(40.6)$ & $0.85(0.54-1.34)$ & 115 & $43(37.4)$ & $0.89(0.68-1.17)$ \\
\hline \multicolumn{7}{|c|}{ Current smoking } \\
\hline No & 203 & $87(42.9)$ & 1.00 & 401 & $157(39.2)$ & 1.00 \\
\hline Yes & 30 & $17(56.7)$ & $1.28(0.87-1.87)$ & 38 & $19(50.0)$ & $1.26(0.90-1.76)$ \\
\hline \multicolumn{7}{|c|}{$\mathrm{BMI}\left(\mathrm{kg} / \mathrm{m}^{2}\right)$} \\
\hline$<25$ & 102 & $42(41.2)$ & 1.00 & 186 & $70(37.6)$ & 1.00 \\
\hline$\geq 25$ & 123 & $59(48.0)$ & $1.18(0.87-1.59)$ & 239 & 97 (40.6) & $1.08(0.85-1.38)$ \\
\hline \multicolumn{7}{|c|}{ Number of medical appointments in previous } \\
\hline \multicolumn{7}{|l|}{12 months } \\
\hline$<3$ & 112 & $50(44.6)$ & 1.00 & 172 & $66(38.4)$ & 1.00 \\
\hline$\geq 3$ & 121 & $54(44.6)$ & $1.01(0.76-1.35)$ & 267 & $110(41.2)$ & $1.08(0.85-1.37)$ \\
\hline
\end{tabular}

BMI: body mass index; PR: prevalence ratio; $95 \% \mathrm{Cl}$ : robust $95 \%$ confidence interval adjusted for all variables listed in the table.

$\star p=0.047$

** $p=0.048$ (Wald's test).

indicators included mean systolic and diastolic pressure measurements, and arterial pressure controlled to levels below 160/100mmHg. Mean systolic pressure was similar in the two cohorts, as was prevalence of arterial pressure controlled to below the level mentioned above. However, among men (but not women), diastolic pressure values were observed to decline significantly. This result is consistent with previous observations that it is easier to reduce diastolic pressure values than systolic pressure values 15 . It is important to remember that among older adults it is systolic pressure rather than diastolic pressure that is most strongly associated with increased risk of cardiovascular events 17,18,19.

Control of arterial pressure can be affected by factors such as lack of access to health services, cost of treatment, poor adherence to medication, adverse effects of drugs, inertia of the doctor responsible, non-compliance with treatment standards, unsuitable education of doctors and patients, and health-related behavior 20 . In this study, successful control of arterial hypertension does not seem to have been determined by access to health services and to treatment, given that the number of medical appointments showed no association with the event, and in 2008the proportion of hypertensive patients treated stood at $91 \%$. Healthrelated behavior (tobacco use and physical activity) and BMI also showed no association with appropriate control of arterial hypertension in either cohort. Only schooling showed an association with appropriate control of arterial hypertension in both the more recent and the earlier cohorts.

One explanation for the association between more schooling and appropriate control of arterial hypertension may be improved understanding and assimilation of medical prescription and its importance 21,22 . The association with schooling observed in this study is consistent with previous observations made among participants in 
the Bambuí cohort of older adults. A qualitative study showed that people were generally clear about the need for treatment to control arterial pressure. However, although most of the participants reported that they followed the treatment, it was clear from their accounts that many of them did not follow their medical prescription correctly. Overall, it was clear from the accounts that the absence of symptoms led many of them to feel they were not ill, and accordingly to underestimate the importance of continuing to use the medication. Thus, medication was often interrupted and resumed only with the advent of symptoms which, in their view, indicated increased arterial pressure ${ }^{23}$. Such behavior may explain, at least partially, the persistence of poor pressure control in the population studied.

This study has advantages and limitations. The advantages include the population base and the standardization of methods and data collection at the baseline and $11^{\text {th }}$ year follow-up. One further advantage was the low level of participant loss to follow-up, which reduced the likelihood of non-participation bias. Meanwhile, the response rate for arterial pressure measurements was slightly higher in the 1997 survey (93\%) than in 2008 (88\%), and that may in some way affect the estimated prevalence of appropriate control of arterial hypertension. However, a sensitivity analysis showed that the results obtained would not be affected even if all non-participants in the 2008 survey had appropriately controlled arterial pressure ( $p=0.196$; details not shown). Lastly, it must be emphasized that this study was conducted using the population of the Bambuí cohort of older adults, and the results may not be generalizable to other elderly populations.

Lack of success in controlling arterial pressure at appropriate levels, in spite of advances in drug therapy and access to treatment, is a phenomenon that has recently be termed the "hypertension paradox" 24 . The persistence of low levels of controlled arterial hypertension in this study occurred in a context of improved schooling, health-related behavior, awareness of the condition of being hypertensive, use of anti-hypertensive drugs, and number of medical appointments. These results show that these improvements were not enough to increase appropriate control of arterial hypertension in the population studied. The results underline the need for complementary measures - possibly to increase adherence to treatment - in order to improve control of existing arterial hypertension.

\section{Resumo}

Foram examinadas diferenças de coorte entre nascidos em 1916-1926 e em 1927-1937 no controle da hipertensão entre participantes do Estudo de Coorte de Idosos de Bambuí. Foram utilizados dados dos participantes hipertensos com 71-81 anos de idade da linha de base ( $n=$ 313) e do 11 o ano de seguimento $(n=484)$. A prevalência dos que sabiam ser hipertensos $(70,9 \%$ e $81,2 \%$, respectivamente) e a mediana de consultas médicas nos últimos 12 meses ( 2 e 3 , respectivamente) e do uso de drogas anti-hipertensivas $(74,4 \%$ e $90,7 \%$, respectivamente) aumentaram significativamente na coorte recente em comparação à antiga. Entretanto, a prevalência do con- trole adequado da hipertensão entre tratados $(<140 /<$ $90 \mathrm{mmHg}$ ) foi semelhante nas duas coortes $(44,6 \%$ e 40,1\%; $p=0.255$ ). Na análise multivariada, a escolaridade foi o único fator independentemente associado ao controle adequado da hipertensão arterial. Apesar do aumento de consultas médicas e do uso de medicamentos na coorte mais jovem, a prevalência do controle adequado da hipertensão permaneceu tão baixa quanto o observado na coorte mais velha.

Hipertensão; Idoso; Estudos de Coortes 


\section{Contributors}

J. O. A. Firmo conceived the project, participated in data collection, analysis and interpretation, drafted the article and approved the final version. S. V. Peixoto and A. I. Loyola Filho participated in the analysis, interpretation of results and critical analysis of the article. E. Uchôa and M. F. Lima-Costa contributed to project conception, data collection, and critical review and final approval of the article.

\section{Acknowledgments}

To FINEP, CNPq and FAPEMIG for funding this study.

\section{References}

1. Ezzati M, Lopez AD, Rodgers A, Vander Hoorn S, Murray CJ; Comparative Risk Assessment Collaborating Group. Selected major risk factors and global and regional burden of disease. Lancet 2002; 360:1347-60.

2. Kearney PM, Whelton M, Reynolds K, Muntner P, Whelton PK, He J. Global burden of hypertension: analysis of worldwide data. Lancet $2005 ; 365$ : 217-23.

3. World Health Organization. The World Health Report 2002: reducing risks, promoting healthy life. Geneva: World Health Organization; 2002.

4. Healthy People. Heart disease and stroke. http:// www.healthypeople.gov/Document/HTML/volu me1/12Heart.htm (accessed on 30/Apr/2010).

5. Kannel WB. Hypertension: reflections on risks and prognostication. Med Clin North Am 2009; 93: 541-58.

6. Graham I, Atar D, Borch-Johnsen K, Boysen G, Burell G, Cifkova R, et al. European guidelines on cardiovascular disease prevention in clinical practice: executive summary. Fourth Joint Task Force of the European Society of Cardiology and Other Societies on Cardiovascular Disease Prevention in Clinical Practice (comprising representatives of nine societies and guest experts). Eur Heart J 2007; 28:2375-414.
7. Departamento de Atenção Básica, Secretaria de Atenção à Saúde, Ministério da Saúde. Hipertensão arterial sistêmica para o Sistema Único de Saúde. Brasília: Ministério da Saúde; 2006. (Cadernos de Atenção Básica, 16).

8. Egan BM, Zhao Y, Axon RN. US trends in prevalence, awareness, treatment, and control of hypertension, 1988-2008. JAMA 2010; 303:2043-50.

9. Keenan NL, Rosendorf KA; Centers for Disease Control and Prevention. Prevalence of hypertension and controlled hypertension - United States, 2005-2008. MMWR Surveill Summ 2011; 60 Suppl:94-7.

10. Leenen FHH, Dumais J, McInnis NH, Turton P, Stratychuk L, Nemeth K, et al. Results of the Ontario survey on the prevalence and control of hypertension. CMAJ 2008; 178:1441-9.

11. Damasceno A, Azevedo A, Silva-Matos C, Prista A, Diogo D, Lunet N. Hypertension prevalence, awareness, treatment, and control in Mozambique: urban/rural gap during epidemiological transition. Hypertension 2009, 54:77-83.

12. Firmo JOA, Barreto SM, Lima-Costa MF. The Bambui Health and Aging Study (BHAS): factors associated with the treatment of hypertension in older adults in the community. Cad Saúde Pública 2003; 19:817-27. 
13. Lima-Costa MF, Firmo JOA, Uchôa E. Cohort profile: the Bambui (Brazil) Cohort Study of Aging. Int J Epidemiol 2010; [Epub ahead of print].

14. Lima-Costa MF, Firmo JOA, Uchôa E. The Bambuí Cohort Study of Aging: methodology and health profile of participants at baseline. Cad Saúde Pública 2011; 27 Suppl 3:S327-35.

15. U.S. Department of Health and Human Services/ National Institutes of Health/National Heart, Lung, and Blood Institute/National High Blood Pressure Education Program. The seventh report of the Joint National Committee on Prevention, Detection, Evaluation, and Treatment of High Blood Pressure. Washington DC: U.S. Department of Health and Human Services/National Institutes of Health/National Heart, Lung, and Blood Institute/National High Blood Pressure Education Program; 2004. (NIH Publication, 04-5230).

16. WHO Collaborating Centre for Drug Statistics Methodology/Norwegian Institute of Public Health. Guidelines for ATC classification and DDD assignment. 13th Ed. Oslo: WHO Collaborating Centre for Drug Statistics Methodology/Norwegian Institute of Public Health; 2009.

17. Bineau S, Dufouil C, Helmer C, Ritchie K, Empana J-P, Ducimetière P, et al. Framingham stroke risk function in a large population-based cohort of elderly people: the 3C study. Stroke 2009; 40:1564-70.
18. Vasan RS, Kannel WB. Strategies for cardiovascular risk assessment and prevention over the life course. Circulation 2009; 120:360-3.

19. D'Agostino RB, Wolf PA, Belanger AJ, Kannel WB. Probability of stroke: a risk profile from the Framingham. Stroke 1991; 22:312-8.

20. Chobanian AV, Bakris GL, Black HR, Cushman WC, Green LA, Izzo Jr. JL, et al. The seventh report of the Joint National Committee on Prevention, Detection, Evaluation, and Treatment of High Blood Pressure: the JNC 7 report. JAMA 2003; 289: 2560-72.

21. Pierin AMG. Orientação sistematizada do paciente hipertenso submetido a tratamento ambulatorial. Rev Esc Enferm USP 1986; 20:193-205.

22. Klein CH, Araújo JWG. Fumo, bebida alcóolica, migração, instrução, ocupação, agregação familiar e pressão arterial em Volta Redonda, Rio de Janeiro. Cad Saúde Pública 1985; 1:160-76.

23. Firmo JOA, Lima-Costa MF, Uchôa E. Projeto Bambuí: maneiras de pensar e agir de idosos hipertensos. Cad Saúde Pública 2004; 20:1029-40.

24. Chobanian AV. Shattuck lecture: the hypertension paradox - more uncontrolled disease despite improved therapy. N Engl J Med 2009; 361:878-87.

Submitted on $29 /$ Nov/2010

Final version resubmitted on 05/Apr/2011 Approved on 09/May/2011 